Macarena Hormanstorfer

Héctor Borodowski

Kevin Nelson

María Jazmín Patrosso

Ingrid Kolland

Luca Italiano

Verónica Inés Casali

Paloma Victoria Barrios

Luis Felipe Hernández

Sepulveda

María Eugenia Tanaro

Cynthia Aldana Petraglia

Alexia Denisse Aguzezko

Cecilia Luna

Carlos Mouse

Ignacio Gandino

Jose Luis Presas

Francisco Paulin

\title{
Prognostic value of static and dynamic biomarkers in COVID-19 patients: a prospective cohort study
}

Internal Medicine Division, Hospital Juan A. Fernández. Buenos Aires, Argentina.

\section{Article history}

Received: 23 November 2020; Revision Requested: 1 February 2021; Revision Received: 22 March 2021; Accepted: 1 April 2021; Published: 31 May 2021

\section{ABSTRACT}

Objective. The aim of this study was to analyze in a prospective cohort of hospitalized COVID-19 patients the relationship between biomarkers levels and their variation within the first 4 days since admission, and prognosis.

Material and methods. Prospective cohort study. Individuals with confirmed diagnosis of covid-19 admitted in our hospital were included. Blood samples were obtained systematically on days 1 and 4 of hospitalization. Levels of RCP, LDH, Ferritin and D-dimer, together with platelets, lymphocytes and neutrophils counts were measured. A combined outcome that included ICU admission and death was considered the primary outcome. Logistic regression analysis was performed.

Results. We included 335 patients with confirmed COVID-19. During their hospitalization, $23(6.8 \%)$ needed ICU admission, and $10(2.9 \%)$ died. In the multivariate analysis, a value of RCP greater than $10 \mathrm{mg} / \mathrm{dl}$ (OR 8.69, Cl95\% 1.45-52), an increase in RCP greater than 20\% (OR 26.08, Cl 95\% 3.21211.3), an increase in LDH greater than 20\% (OR 6.29, Cl 95\% 1.84-21.44), a count of lymphocytes lower than $1500 / \mathrm{mm} 3$ (OR 2.74, Cl 95\% 1.04-7.23), a D-dimer value greater than 550 $\mathrm{ng} / \mathrm{ml}$ (OR 9.8, Cl 95\% 1.78-53.9) and a neutrophi//lymphocyte index greater than $3(0 \mathrm{R} 4.5, \mathrm{Cl} 95 \%$ 1.43-14.19) were all associated with the primary outcome.

Conclusion. Our study shows that the utilization of static and dynamic biomarkers may represent an important tool to assess prognosis of COVID-19 patients.

Keywords: COVID-19, biomarkers, inflammation

Correspondence:

Macarena Hormanstorfer

Internal medicine division, Hospital Juan A. Fernández.

Address: Av. Cerviño 3356 (1425), Buenos Aires, Argentina.

Phone: +54 91139179223

E-mail hormanstorferm@gmail.com
Valor pronóstico de biomarcadores estáticos y dinámicos en pacientes con COVID-19: un estudio de cohorte prospectivo

\section{RESUMEN}

Objetivo. El objetivo de este estudio es analizar en una cohorte prospectiva de pacientes internados por COVID-19, el valor pronóstico de los niveles de biomarcadores y su variación en los primeros cuatro días de internación.

Material y métodos. Estudio de cohorte prospectivo. Se incluyeron individuos con diagnóstico confirmado de COVID-19 ingresados en nuestro hospital. Se obtuvieron muestras de sangre de forma sistemática los dias 1 y 4 de internación. Se midieron los niveles de PCR, LDH, ferritina y dimero-D, junto con recuento de plaquetas, linfocitos y neutrófilos. Una variable de desenlace combinada que incluia la admisión a la $\mathrm{UCl}$ y la muerte se consideró como resultado primario. Se realizó un análisis de regresión logistica.

Resultados. Se incluyeron 335 pacientes con COVID-19 confirmado. Durante su internación, $23(6,8 \%)$ necesitaron ingreso en $\mathrm{UCl}$ y $10(2,9 \%)$ fallecieron. En el análisis multivariado, un valor de PCR superior a $10 \mathrm{mg} / \mathrm{dl}$ (OR 8,69, IC 95\% 1,45-52), un aumento de PCR superior al 20\% (OR 26,08, IC $95 \% 3,21-211,3$ ), un aumento de LDH superior al 20\% (OR 6,29 , IC 95\% 1,84-21,44), un recuento de linfocitos inferior a 1500/mm3 (OR 2,74, IC 95\% 1,04-7,23), un valor de dimero-D superior a $550 \mathrm{ng} / \mathrm{ml}(0 \mathrm{R} 9,8$, IC 95\% 1,78-53,9) y un indice de neutrófilos/linfocitos superior a 3 (OR 4,5, IC 95\% 1,43-14,19) se asociaron con el resultado primario.

Conclusión. Nuestro estudio muestra que la utilización de biomarcadores estáticos y dinámicos puede representar una herramienta importante para evaluar el pronóstico de los pacientes con COVID-19.

Palabras clave: COVID-19, biomarcadores, inflamación. 


\section{INTRODUCTION}

In December 2019, the WHO was warned by the Chinese health authorities about the presence of patients with pneumonia of unknown etiology. Later, the cause would be identified as a virus named SARS-COV-2, and the disease was called COVID-19 [1, 2]. Given the huge number of patients affected by this disease and the magnitude of the challenge, it is necessary to develop tools to accurately predict the risk of an unfavorable evolution. This could help to optimize the utilization of resources in the management of COVID-19 patients.

Objective clinical parameters have been studied with the aim identifying those patients at risk of presenting severe forms of the disease. Also, several scores have been proposed with that objective, with good results [3-6]. As an example, the modified NEWS score has proved to be an interesting tool to assess the severity of the disease and prognosis in COVID 19 patients [6]. However, all those scores share the same defect, they cannot anticipate the clinical worsen, because the were built with clinical parameters. The ideal predictor would be one that anticipates the deterioration, when patients are still stable.

Objective laboratory parameters with the ability to discriminate cases with worse prognosis could help to alert physicians before the complications appear. In this clinical scenario, the utilization of serum biomarkers could represent an important help. Focusing on their ability to predict prognosis, various authors studied different biologic parameters.

During the beginning of the pandemic a group of researchers in China showed the association between some biomarkers, such as elevated CRP and Iymphopenia, and an increase in the requirement of ICU admission, intubation or death $[7,8]$. This initial information was reproduced by new studies and confirmed by a meta-analysis [9-11]. However, these studies considered only the values at patients admission, leaving aside the change in the biomarkers values during the hospitalization. Given that patients with severe forms of COVID-19 have shown to worsen after 5-7 days since the beginning of symptoms, it makes sense to study the association between the change in biomarkers values in the first 4 days, and the development of complications $[12,13]$. Few studies have focused on this hypothesis. A group of authors found association between the variation of biomarkers values during hospitalization and prognosis in a retrospective study, supporting this strategy [14]. However, prospective cohort studies designed to test this strategy and define clear cut-off points are lacking.

The aim of this study was to analyze in a prospective cohort of hospitalized COVID-19 patients, the relationship between the variations of biomarkers values within the first 4 days since admission and prognosis.

\section{MATERIAL AND METHODS}

We conducted a prospective cohort study in Juan A. Fer- nandez Hospital, a public academic healthcare institution located in Buenos Aires city, designated to give attention to suspected and confirmed cases of COVID-19. Individuals with diagnosis of COVID-19 of 18 years old or more who were attended between April 24 and June 24 were included. The diagnosis of COVID-19 was confirmed with a positive RT-PCR assay for SARS-CoV-2 in nasopharyngeal swab.

Data was collected in a structured form, including: demographic and epidemiological information, comorbidities (diabetes, obesity, hypertension, congestive heart failure, coronary disease, HIV infection, chronic kidney disease, alcohol abuse, smoking history, COPD, asthma, and tuberculosis), signs and symptoms at disease onset, vital signs (blood pressure, heart and respiratory rate, temperature and blood oxygen saturation by pulse oximetry), blood test and chest image results. A member of the data management team, reviewed by a second member of the same team, loaded data submitted by physicians on a paper form into a digital database. The diagnosis of pneumonia was defined as the presence of compatible signs and symptoms (fever with cough or dyspnea) with imaging confirmation. The images used to make pneumonia diagnosis were chest x-ray, lung ultrasound, and chest CT (performed in patients in whom the diagnosis of pneumonia was still not clear after the realization of x-ray or lung ultrasound).

Blood samples were obtained systematically on days 1 and 4 of hospitalization. Levels of RCP and LDH were measured on both samples, together with platelets, lymphocytes and neutrophils counts. Ferritin and D-dimer levels were measured only on day 4 . We calculated the change in the value of the biomarkers between day 1 and 4 . Their values were studied as prognostic predictors. RCP levels were measured by immunoturbidimetry, with a cut off value of $0.6 \mathrm{mg} / \mathrm{dl}$. LDH levels were measured by an enzymatic method (IFCC), with a cut off value of $200 \mathrm{U} / \mathrm{ml}$. Ferritin was measured by chemiluminescence, with a reference value of 11-306 $\mathrm{ng} / \mathrm{ml}$. D-dimer was measured by ELISA, with a cut off value of $230 \mathrm{ng} / \mathrm{ml}$. We used the NEWS score to assess patient's severity at admission. We compared NEWS value at day 1 and day 4, with the aim of knowing if the change in biomarkers values during the first days was associated with a change in clinical status previous to the development of the outcomes.

Two outcomes were analyzed. A combined outcome that included ICU admission and death was considered the primary outcome. Prolonged hospitalization (defined as a time between admission and discharge larger than 10 days) was analyzed as a secondary outcome.

Statistical analysis. We grouped patients according to the occurrence or not of each outcome. Values of the different biomarkers were compared using T-test, or Mann-Whitney test, depending on the presence or not of normal distribution. When differences between groups were statistically significant, univariate logistic regression was performed. Biomarkers values were categorized according to cut-off points defined by receiver operating curve $(\mathrm{ROC})$ analysis. Statistical significance was analyzed with Wald test. Variables with a $p$ value of 0.1 or 
lower were considered candidates for the multivariate analysis. Variables were adjusted to the patients age, and to the need of supplemental oxygen, since both covariables have shown in different publications to have a significant impact on prognosis [15-17]. The $O R$ of the change of a biomarker between days 1 and 4 was also adjusted to the baseline value of the same biomarker. ORs and their Cl95\% were reported.

The manuscript was written according to the STROBE initiative for the communication of observational studies [18]. The Institutional Ethics Committee of Fernandez Hospital reviewed and approved the second version of the protocol dated on May 11, 2020. Disposition number: DI-2020-393-GCABAHGAJAF

\section{RESULTS}

Between April 24 and June 24 of 2020, 335 patients with confirmed COVID-19 were admitted in the Fernandez Hospital. Baseline characteristics of patients are shown in Table 1. The mean (SD) age was 44.85 years (17.17), with mild predominance of male gender (52\%) The most common symptoms at baseline were fever (60.36\%) and cough (60.06\%). Obesity and hypertension were the most common comorbidities (21.02\% and $17.37 \%$ respectively). A total of 190 patients (57.05\%) received the diagnosis of pneumonia, and $17.72 \%$ needed supplementary oxygen. Regarding the evolution during hospitalization, 16.92\% developed respiratory insufficiency, 6.87\% needed ICU admission, and 2.99\% died.

The occurrence of the combined outcome ICU admission or death was associated with higher values of RPC, LDH, D-dimer, and Neutrophils/lymphocytes index, and a lower lymphocytes count. Also, the change in RPC and LDH between days 1 and 4 were associated with this outcome (table 2).

On the other hand, a prolonged hospitalization was associated with higher values of RPC, LDH, ferritin, D-dimer, and Neutrophils/lymphocytes index, and a lower lymphocytes count. The change in RPC between days 1 and 4 was also associated with prolonged hospitalization (table 3 ).

The logistic regression analysis to predict ICU admission or death is shown in table 4. A RCP value greater than 10 $\mathrm{mg} / \mathrm{dl}$, a change in RPC between days 1 and 4 greater than $20 \%$, a value of $L D H$ above $400 \mathrm{U} / \mathrm{ml}$, a change in $L D H$ value greater than 20\%, a value of lymphocytes below $1500 / \mathrm{mm} 3$, a D-dimer value above $550 \mathrm{ng} / \mathrm{ml}$, and a NLI greater than 3 were all significantly associated with the outcome in the univariate and multivariate analysis. The higher $\mathrm{OR}$ was observed with the increase of RCP greater than 20\% (adjusted OR 26.08, Cl95\% 3.21-211.3).

The logistic regression analysis to predict prolonged hospitalization is shown in table 5 . A RCP value greater than $10 \mathrm{mg} /$

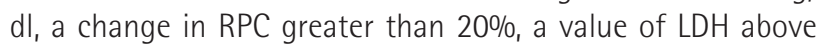
$400 \mathrm{U} / \mathrm{ml}$, a change in LDH value greater than $20 \%$, a value of lymphocytes below $1500 / \mathrm{mm} 3$, a D-dimer value above $550 \mathrm{ng} /$ $\mathrm{ml}$, a NLI greater than 3, and a value of ferritin greater than $900 \mathrm{ng} / \mathrm{ml}$ were all significantly associated with the outcome

\begin{tabular}{|c|c|c|}
\hline Table 1 & \multicolumn{2}{|c|}{$\begin{array}{l}\text { Demographic and clinical characteristics } \\
\text { of the cohort }(\mathrm{N}=335)\end{array}$} \\
\hline Age, mean $(S$ & & 44.85 (17.17) \\
\hline Male gender, & & $177(52)$ \\
\hline Diagnosis of & nia, n (\%) & $190(57.05)$ \\
\hline \multicolumn{3}{|c|}{ Comorbidities } \\
\hline Obesity, n & & $70(21.02)$ \\
\hline$H I V, n(\%)$ & & $4(1.2)$ \\
\hline Chronic ki & sease, n (\%) & $6(1.8)$ \\
\hline Current sn & & $32(9.58)$ \\
\hline Asthma, $n$ & & $20(5.99)$ \\
\hline Hypertens & & $58(17.37)$ \\
\hline Congestiv & Failure, $n(\%)$ & $4(1.2)$ \\
\hline Coronary & $n(\%)$ & $4(1.2)$ \\
\hline ACEls, $n(0$ & & $25(7.53)$ \\
\hline ARBs, $n(0)$ & & $10(3.01)$ \\
\hline \multicolumn{3}{|c|}{ Manifestations } \\
\hline Fever, $\mathrm{n}(0)$ & & 201 (60.36) \\
\hline Dyspnea, 1 & & 112 (33.63) \\
\hline Diarrhea, I & & 49 (14.71) \\
\hline Malaise, $n$ & & 142 (42.64) \\
\hline Cough, $n$ & & $200(60.06)$ \\
\hline Sore throa & & 95 (28.53) \\
\hline Headache & & 165 (49.55) \\
\hline Myalgia, $n$ & & 105 (31.63) \\
\hline Arthralgia & & $58(17.42)$ \\
\hline Anosmia 0 & usia, n (\%) & $105(32.51)$ \\
\hline \multicolumn{3}{|c|}{ Physical exam } \\
\hline Systolic bl & ssure, mean (SD) & $121.73(15.33)$ \\
\hline Temperatu & $n(S D)$ & $16.79(0.93)$ \\
\hline Heart rate & & $90.82(14.27)$ \\
\hline Respirator & nean (SD) & $20.47(4.87)$ \\
\hline Oxygen sa & , mean (SD) & $96.04(2.45)$ \\
\hline Suplemen & gen, $n(\%)$ & 56 (17.72) \\
\hline NEWS sco & mission, median (IOR) & $2(1-4)$ \\
\hline \multicolumn{3}{|l|}{ Blood tests } \\
\hline Platelets, I & (IOR) & $199(155-250)$ \\
\hline Lymphocy & ${ }^{3}$, mean (SD) & $1457.4(564.6)$ \\
\hline $\mathrm{RCP}(\mathrm{mg} / \mathrm{c}$ & an $(\mathrm{IQR})$ & $3.39(0.9-6.94)$ \\
\hline $\mathrm{LDH}(\mathrm{U} / \mathrm{ml}$ & In (IOR) & $246.5(200-310)$ \\
\hline CPK $(\mathrm{mg} / \mathrm{d}$ & an, (SD) & $64.5(44-101)$ \\
\hline D Dimer (r & nean (SD) & 265 (226.5-397) \\
\hline Ferritin (n & ean (SD) & $414.6(157-730)$ \\
\hline \multicolumn{3}{|l|}{ Evolution } \\
\hline Respirator & iciency, n (\%) & 55 (16.92) \\
\hline Mechanic & ation, n (\%) & $13(4.59)$ \\
\hline ICU admis & & $23(6.87)$ \\
\hline Death, n ( & & $10(2.99)$ \\
\hline
\end{tabular}




\begin{tabular}{|c|c|c|c|c|}
\hline \multirow[t]{2}{*}{ Table 2} & \multicolumn{4}{|c|}{$\begin{array}{l}\text { Comparison of biomarker value according to the occurrence of the combined } \\
\text { outcome ICU admission or death. }\end{array}$} \\
\hline & & ICU admission or death & No ICU admission nor death & $P$ value \\
\hline \multicolumn{2}{|c|}{ RCP $(\mathrm{mg} / \mathrm{dl})$, median $(\mathrm{IOR})$} & $9(4.6-17)$ & $2.82(0.77-6.34)$ & $<0.0001$ \\
\hline \multicolumn{2}{|c|}{ Change in RCP\%, median (IOR) } & $59.12(-74.1$ to 120.9$)$ & $-6.75(-51.6$ to 56.6$)$ & 0.0207 \\
\hline \multicolumn{2}{|c|}{ LDH (U/ml), median (IQR) } & $294(230-418)$ & $240(195-300)$ & 0.0057 \\
\hline \multicolumn{2}{|c|}{ Change in LDH\%, median (IOR) } & 22 (-2.8 to 39.1$)$ & $0.85(-13.7$ to 13$)$ & 0.0171 \\
\hline \multicolumn{2}{|c|}{ Ferritin (ng/ml), median (IQR) } & $447(325-561)$ & $412.2(151.4-770)$ & 0.693 \\
\hline \multicolumn{2}{|c|}{ D-dimer (ng/ml), median (IOR) } & $694(365-1900)$ & $261.5(226-368)$ & 0.0009 \\
\hline \multicolumn{2}{|c|}{ Platelets/mm³ ${ }^{3}$ median (IQR) } & $189(155-242)$ & $199.5(155-251)$ & 0.786 \\
\hline \multicolumn{2}{|c|}{ Change in platelets $\%$, median (IOR) } & 10.81 (-6.4 to 31.7$)$ & $18.5(0.46-41.5)$ & 0.275 \\
\hline \multicolumn{2}{|c|}{ Lymphocytes/mm³ ${ }^{3}$ mean (SD) } & $1229.1(473.4)$ & $1685.7(705.5)$ & 0.0007 \\
\hline \multicolumn{2}{|c|}{ Change in lymphocytes \%, median (IOR) } & $-1.95(-26$ to 27.5$)$ & $5.52(-10.1$ to 35.8$)$ & 0.349 \\
\hline \multicolumn{2}{|c|}{ Neutrophils/lymphocytes index, median (IOR) } & $6(3.9-7.7)$ & $2.64(1.64-4.3)$ & $<0.0001$ \\
\hline
\end{tabular}

\begin{tabular}{|c|c|c|c|c|}
\hline \multirow[t]{2}{*}{ Table 3} & \multicolumn{4}{|c|}{$\begin{array}{l}\text { Comparison of biomarker values according to the occurrence of the event prolonged } \\
\text { hospitalization. }\end{array}$} \\
\hline & & Prolonged hospitalization & No prolonged hospitalization & $P$ value \\
\hline \multicolumn{2}{|c|}{$\mathrm{RCP}(\mathrm{mg} / \mathrm{dl})$, median (IOR) } & $2.77(0.77-8.72)$ & $1.7(0.55-4.9)$ & $<0.0001$ \\
\hline \multicolumn{2}{|c|}{ Change in RCP\%, median (IQR) } & $18.19(-44.1$ to 114.4$)$ & $-014.9(-60.4$ to 24.1$)$ & 0.0113 \\
\hline \multicolumn{2}{|c|}{ LDH (U/ml), median (IOR) } & $255(210-335)$ & $233(192-291)$ & 0.0039 \\
\hline \multicolumn{2}{|c|}{ Change in LDH\%, median (IOR) } & $2.9(-12.1$ to 23.1$)$ & 1.99 (-15.5 to 12.2$)$ & 0.199 \\
\hline \multicolumn{2}{|c|}{ Ferritin (ng/ml), median (IOR) } & $465(225-980)$ & 338 (103-599) & 0.015 \\
\hline \multicolumn{2}{|c|}{ D-dimer ng/ml, median (IQR) } & $290.5(237-1-25)$ & $247(218-330)$ & 0.0155 \\
\hline \multicolumn{2}{|c|}{ Platelts/mm³ ${ }^{3}$ median (IQR) } & $196(159-247)$ & $200(153-253)$ & 0.694 \\
\hline \multicolumn{2}{|c|}{ Change in platelets \%, median (IOR) } & $17.9(-1.79$ to 36.1$)$ & $18.2(0.49-44.5)$ & 0.583 \\
\hline \multicolumn{2}{|c|}{ Lymphocytes/mm³ ${ }^{3}$ mean (SD) } & $1498.2(699.6)$ & $1760.4(722.6)$ & 0.0008 \\
\hline \multicolumn{2}{|c|}{ Change in lymphocytes $\%$, median (IOR) } & $2.33(-13.9$ to 27.5$)$ & $8.13(-8$ to 39.2$)$ & 0.1703 \\
\hline \multicolumn{2}{|c|}{ Neutrophils/lymphocytes index, median (IQR) } & $3.4(2-6)$ & $2.5(1.5-4.1)$ & $<0.0001$ \\
\hline
\end{tabular}

in the univariate analysis. After adjusting for potential confounders, only an increase in RCP or LDH values greater than $20 \%$ and the baseline value of ferritin conserved statistical significance. The higher OR was observed with the baseline value of ferritin (adjusted OR 3.36, Cl95\% 1.11-10.11). The median (IQR) of NEWS score at day 1 was not significantly different from the score at day 4 [2 (1-4) vs $2(1-4) ; p=0.13]$.

\section{DISCUSSION}

Our study shows a set of biomarkers (RCP, LDH, lymphocytes count, ferritin, D-dimer and NLI) which baseline levels can predict a poor outcome in patients with COVID-19. Also, we found that a dynamic evaluation of some of these biomarkers (RCP and LDH) is another important tool for the COVID-19 patient's management.

During the course of COVID-19 disease, dysregulation of the inflammatory immune response and increased proinflammatory cytokine/chemokine production results in a dynamic process that received the name of "cytokine storm", which is associated with tissue damage and thus respiratory or multiple organ failure [19-22]. Previous data in the literature shows the role of biomarkers determinations to identify these patients and predict worse prognostic [10,23]. Our study reaffirms these findings and introduces the concept of dynamic change in biomarkers as another factor associated with the severity 


\begin{tabular}{|c|c|c|c|c|c|c|}
\hline \multirow[t]{2}{*}{ Table 4} & \multicolumn{6}{|c|}{ Univariate and multivariate logistic regression analysis to predict ICU admission or death. } \\
\hline & Unadjusted OR & $\mathrm{Cl} 95 \%$ & P value & Adjusted OR & $\mathrm{Cl} 95 \%$ & Pvalue \\
\hline $\mathrm{RCP} \geq 10 \mathrm{mg} / \mathrm{dl}$ & 8.14 & $3.25-20.35$ & $<0.0001$ & 8.69 & $1.45-52.08$ & 0.018 \\
\hline Change in $\mathrm{RCP} \geq 20 \%$ & 11.41 & $2.45-52.95$ & 0.002 & 26.08 & $3.21-211.3$ & 0.002 \\
\hline $\mathrm{LDH} \geq 400 \mathrm{U} / \mathrm{dl}$ & 3.96 & $1.42-11.06$ & 0.008 & 1.66 & $0.38-7.17$ & 0.06 \\
\hline Change in LDH $\geq 20 \%$ & 4.53 & $1.57-13.04$ & 0.005 & 6.29 & $1.84-21.44$ & 0.003 \\
\hline Lymphocytes $<1500 / \mathrm{mm}^{3}$ & 4.25 & $1.76-10.28$ & 0.001 & 2.74 & $1.04-7.23$ & 0.041 \\
\hline D-dimer $\geq 550 \mathrm{ng} / \mathrm{ml}$ & 10.3 & $2.6-40.78$ & 0.001 & 9.8 & $1.78-53.9$ & 0.009 \\
\hline$N L I \geq 3$ & 8.46 & $2.87-24.95$ & $<0.0001$ & 4.5 & $1.43-14.19$ & 0.01 \\
\hline
\end{tabular}

NLI: neutrophil/lymphocyte index

\begin{tabular}{|c|c|c|c|c|c|c|}
\hline \multirow[t]{2}{*}{ Table 5} & \multicolumn{6}{|c|}{ Univariate and multivariate logistic regression analysis to prolonged hospitalization } \\
\hline & Unadjusted OR & $\mathrm{Cl} 95 \%$ & $P$ value & Adjusted OR & $\mathrm{Cl} 95 \%$ & Pvalue \\
\hline $\mathrm{RCP} \geq 10 \mathrm{mg} / \mathrm{dl}$ & 2.87 & $1.37-6.02$ & 0.005 & 1.18 & $0.44-3.16$ & 0.732 \\
\hline Change in $\mathrm{RCP} \geq 20 \%$ & 2.6 & $1.34-5.02$ & 0.004 & 1.18 & $0.44-3.16$ & 0.013 \\
\hline $\mathrm{LDH} \geq 400 \mathrm{U} / \mathrm{ml}$ & 2.96 & $1.28-6.83$ & 0.011 & 1.73 & $0.65-4.64$ & 0.27 \\
\hline Change in $\mathrm{LDH} \geq 20 \%$ & 2.74 & $1.26-5.94$ & 0.011 & 2.75 & $1.23-6.13$ & 0.013 \\
\hline Lymphocytes $<1500 / \mathrm{mm}^{3}$ & 1.79 & $1.14-2.8$ & 0.01 & 1.49 & $0.92-2.43$ & 0.101 \\
\hline D-dimer $\geq 550 \mathrm{ng} / \mathrm{ml}$ & 2.74 & $0.98-7.61$ & 0.052 & 2.39 & $0.82-6.97$ & 0.109 \\
\hline Ferritin $\geq 900 \mathrm{ng} / \mathrm{ml}$ & 3.53 & $1.22-10.1$ & 0.019 & 3.36 & $1.11-10.11$ & 0.031 \\
\hline$N L I \geq 3$ & 2 & $1.28-3.13$ & 0.002 & 1.59 & $0.97-2.6$ & 0.062 \\
\hline
\end{tabular}

NLI: neutrophil/lymphocyte index

and progression of COVID-19. Few of the previous studies in the literature analyze this dynamic approach. R. Chen et al. retrospectively investigated the value of biomarkers upon admission and longitudinal variation during the hospitalization and revealed clear differences between survivors and deceased patients. Progressive increase in neutrophils, basophils, and IL19 were identified as risk factors for unfavorable evolution in COVID-19 [19]. In another retrospective study, dynamic variation of D-dimer and the neutrophil-lymphocyte ratio (NLR) were even better predictors of bad prognosis than their isolated baseline value [24].

In the present study, we prospectively analyzed not only the clinical significance of static value of RCP, LDH, platelets, lymphocytes, neutrophils, Ferritin and D-dimer (day 4) but also the dynamic change in RCP, LDH, platelets and Neutrophils/ lymphocytes index in the first four days since admission, and we expressed this change in percentage value. We found that an increase in the levels of RCP between days 1 and 4 greater than $20 \%$ has more impact on prognosis than its baseline levels. This impact in prognosis increases after adjusting for age (the most important prognostic factor reported) and severity in the multivariate analysis $[15,25]$. Interestingly, this effect is independent from the RCP baseline value. Also, the values of the NEWS score between days 1 and 4 were not significantly different, which means that the change in biomarkers values was previous to the change in clinical status. This fact highlights the importance of this approach.

It is important to mention that our cohort had a relatively low incidence of supplemental oxygen requirement, $\mathrm{UCl}$ admission and death compared with other studies [7]. This fact is related to the admission criteria used at the beginning of the pandemic, when patients with mild forms of the disease where admitted with the aim of isolate them from the community.

Results of the Randomised Evaluation of COVID-19 Therapy (RECOVERY) trial showed a reduction of mortality in patients randomized to receive dexamethasone, compared with those who received standard care. This benefit was observed only in patients who required supplemental oxygen or mechanical ventilation [26]. As was previously mentioned, the dysregulation of inflammatory immune response plays a key role in the development of tissue damage and respiratory or multiple organ failure. Keller et al. extended the results of the RECOVERY trial, and identified cutoff points for CRP levels that 
can help to define which patients are more likely to be benefited or harmed with corticosteroids treatment [27].

Our study has some limitations. First, it was performed in one single center, what implies the possible introduction of selection bias. Second, not all biomarkers were studied in a dynamic way (i.e. D-dimer). Third, we did not perform an active follow up after discharge, what implies that some patients could have been admitted again in another center.

To our knowledge, this is the first study that analyzes the dynamic behaviour of biomarkers in a prospective cohort design. The biomarkers that were analyzed in this study are widely available. His fact highlights the importance of our results and their potential impact in clinical practice. Patients with a biomarker's pattern that predicts a poor outcome could receive a more intensive monitoring, and an early treatment with steroids. Additional studies are needed to further elucidate the role of biomarkers and their dynamic change to predict the clinical course and guide therapeutic decisions. However, we believe that our results can represent a contribution to that approach.

\section{FUNDING}

None to declare.

\section{CONFICTS OF INTEREST}

All the authors state that they have no conflicts of interest.

\section{REFERENCES}

1. Zhu N, Zhang D, Wang W, Li X, Yang B, Song J, et al. A Novel Coronavirus from Patients with Pneumonia in China, 2019. N Engl J Med. 2020;382(8):727-733. doi:10.1056/nejmoa2001017

2. Phelan AL, Katz R, Gostin LO. The Novel Coronavirus Originating in Wuhan, China: Challenges for Global Health Governance. JAMA - J Am Med Assoc. 2020;323(8):709-710. doi:10.1001/jama.2020.1097

3. Haimovich A, Ravindra NG, Stoytchev S, Young HP, PerryWilson $F$, Van Dijk D, et al. Development and validation of the quick COVID-19 severity index (qCSI): a prognostic tool for early clinical descompensatio. Annals of Emergency Medicine, 2020. doi: 10.1016/j.annemergmed.2020.07.022

4. Liang $W_{\text {, Liang }} \mathrm{H}_{1} \mathrm{Ou} \mathrm{L}$, Chen $\mathrm{B}$, Chen $\mathrm{A}$, Li $\mathrm{C}$, et al. Development and validation of a clinical risk score to predict the ocurrence of critical illness in hospitalized patients with COVID-19. JAMA Intern Med. 2020; 180 (8): 1081-1089. doi: 10.1001/jammainternmed.2020.2033

5. Scherag A, Rubenfeld G, Kahn JM, Shankar-hari M, Singer M. Assessment of Clinical criteria for sepsis for the third international consensus definitions for sepsis and septic shock (Sepsis-3). 2016; 315(8): 762-774. doi: 10.1001/jama.2016.0288

6. Liao $X$, Wang $B$, Kang $Y$. Novel coronavirus infection during the 2019-2020 epidemic: preparing intensive care units- the experience in Sichuan Province, China. Intensive Care Med 2020;46:357360. doi: 10.1007/s00134-020-05954-2
7. Guan W, Ni Z, Hu Y, Liang W, Ou C, He J, et al. Clinical characteristics of coronavirus disease 2019 in China. N Engl J Med. 2020. doi:10.1056/NEJMoa2002032

8. Liu Y, Yang Y, Zhang C, Huang F, Wang F, Yuan J, et al. Clinical and biochemical indexes from 2019-nCoV infected patients linked to viral loads and lung injury. Sci China Life Sci. 2020;63(3):364-374. doi: 10.1007/s11427-020-1643-8

9. Terpos E, Ntanasis-Stathopoulos I, Elalamy I, Kastritis E, Sergentanis $\mathrm{T}$, Politou $\mathrm{M}$ et al. Hematological findings and complications of COVID-19. Am J Hematol. 2020;95(7):834-847. doi:10.1002/ ajh.25829

10. Kermali M, Khalsa RK, Pillai K, Ismail Z, Harky A. The role of biomarkers in diagnosis of COVID-19 - A systematic review. Life Sci. 2020 Aug 1;254:117788. doi: 10.1016/j.Ifs.2020.117788

11. Henry BM, De Oliveira MHS, Benoit S, Plebani M, Lippi G. Hematologic, biochemical and immune biomarker abnormalities associated with severe illness and mortality in coronavirus disease 2019 (COVID-19): A meta-analysis. Clin Chem Lab Med. 2020;58(7):10211028. doi:10.1515/cclm-2020-0369

12. Bouadma L, Lescure FX, Lucet JC, Yazdanpanah Y, Timsit JF. Severe SARS - CoV - 2 infections: practical considerations and management strategy for intensivists. Intensive Care Med. 2020; 46(4):579-582 doi:10.1007/s00134-020-05967-x

13. Siddiqi HK, Mehra MR. COVID-19 Illness in Native and Immunosuppressed States: A Clinical-Therapeutic Staging Proposal. J Hear Lung Transplant. 2020. doi:10.1016/j.healun.2020.03.012

14. Chen $R$, Liang $W$, Jiang $M$, Guan $W$, Zhan $C$, Wang $T$, et al. Risk Factors of Fatal Outcome in Hospitalized Subjects With Coronavirus Disease 2019 From a Nationwide Analysis in China. Chest. 2020;158(1):97-105. doi:10.1016/j.chest.2020.04.010

15. Wu C, Chen X, Cai Y, Xia J, Zhou X, Xu S, et al. Risk Factors Associated with Acute Respiratory Distress Syndrome and Death in Patients with Coronavirus Disease 2019 Pneumonia in Wuhan, China. JAMA Intern Med. 2020; 180(7): 1-11. doi:10.1001/jamainternmed.2020.0994

16. Wang D, Hu B, Hu C, Zhu F, Liu X, Zhang J, et al. Clinical Characteristics of 138 Hospitalized Patients with 2019 Novel Coronavirus-Infected Pneumonia in Wuhan, China. JAMA - J Am Med Assoc. 2020: 323(11): 1061-1069. doi:10.1001/jama.2020.1585

17. Wolff $D$, Nee $S$, Hickey N, Marscholek M. Risk factors for Covid-19 severity and fatality a structured literature.Infection, 2020;1-14. doi:10.1007/s15010-020-01509-1

18. Von Elm E, Altman DG, Egger M, Pocock SJ, Gotzsche PC, Vandenbroucke JP. Directrices para comunicación de estudios observacionales. Gac Sanit. 2008; 22:144-50. doi:10.1371/journal. pmed.0040296

19. Manjili RH, Zarei M, Habibi M, Manjili MH. COVID-19 as an Acute Inflammatory Disease. J Immunol. 2020;205(1):12-19. doi:10.4049/ jimmunol.2000413

20. Huang $C$, Wang $Y$, Li $X$, Ren L, Zhao J, Hu Y, et al. Clinical features of patients infected with 2019 novel coronavirus in Wuhan, China. Lancet. 2020;395(10223):497-506. doi:10.1016/S01406736(20)30183-5 
21. Qin C, Zhou L, Hu Z, Zhang S, Yang S, Tao Y, et al. Dysregulation of Immune Response in Patients with COVID-19 in Wuhan, China. Clin Infect Dis. 2020; 71(15):762-768. doi: 10.1093/cid/ciaa248

22. Ye $\mathrm{Q}$, Wang $\mathrm{B}, \mathrm{Mao} J$. The pathogenesis and treatment of the 'Cytokine Storm" in COVID-19.' J Infect. 2020;80(6):607-613. doi:10.1016/j.jinf.2020.03.037

23. Sonja A. Rasmussen, MD, MS JCS. Prognostic value of interleukin-6, C-reactive protein, and procalcitonin in patients with COVID-19.J Clin Virol. 2020;127:104370. doi: 10.1016/j.jcv.2020.104370.

24. Ye $W$, Chen $G$, Li $X$, Lan $X_{1}$ Ji $C$, Hou M, et al. Dynamic changes of D-dimer and neutrophil-lymphocyte count ratio as prognostic biomarkers in COVID-19. Respir Res. 2020 ;21(1):169. doi: 10.1186/ s12931-020-01428-7.

25. Zhou F, Yu T, Du R, Fan G, Liu Y, Liu Z, et al. Clinical course and risk factors for mortality of adult inpatients with COVID-19 in Wuhan, China: a retrospective cohort study. Lancet. 2020; 395(10229):1054-1062. doi: 10.1016/S0140-6736(20)30566-3

26. Horby P, Lim WS, Emberson JR, Mafham M, Bell JL, Linsell L, et al. RECOVERY Collaborative Group. Dexamethasone in Hospitalized Patients with Covid-19 - Preliminary Report. N Engl J Med. 2020: NEJMoa2021436. doi: 10.1056/NEJMoa2021436.

27. Keller MJ, Kitsis EA, Arora S, Chen JT, Agarwal S, Ross MJ, et al. Effect of systemic glucocorticoids on mortality or mechanical ventilation in patients with COVID-19. J Hosp Med. 2020;15(8):489-493. doi:10.12788/jhm.3497 